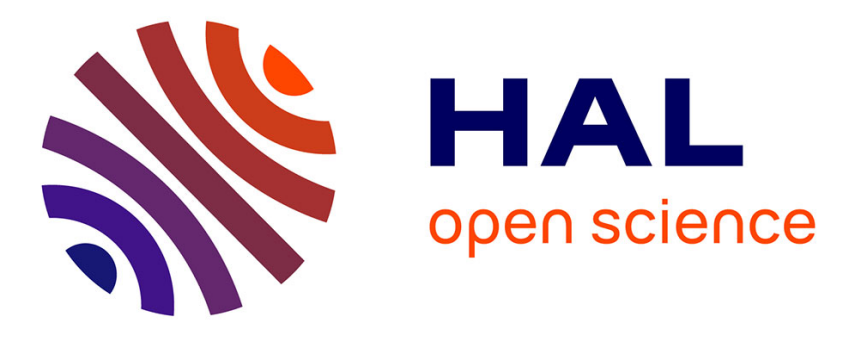

\title{
Spatial aspects of gene flow between rapeseed varieties and volunteers
}

Nathalie Colbach, Nicolas Molinari, Jean-Marc Meynard, Antoine Messéan

\section{To cite this version:}

Nathalie Colbach, Nicolas Molinari, Jean-Marc Meynard, Antoine Messéan. Spatial aspects of gene flow between rapeseed varieties and volunteers. Agronomy for Sustainable Development, 2005, 25 (3), pp.355-368. hal-00886294

\section{HAL Id: hal-00886294 https://hal.science/hal-00886294}

Submitted on 1 Jan 2005

HAL is a multi-disciplinary open access archive for the deposit and dissemination of scientific research documents, whether they are published or not. The documents may come from teaching and research institutions in France or abroad, or from public or private research centers.
L'archive ouverte pluridisciplinaire HAL, est destinée au dépôt et à la diffusion de documents scientifiques de niveau recherche, publiés ou non, émanant des établissements d'enseignement et de recherche français ou étrangers, des laboratoires publics ou privés. 


\title{
Spatial aspects of gene flow between rapeseed varieties and volunteers
}

\author{
Nathalie COLBACH ${ }^{\mathrm{a} *}$, Nicolas MOLINARI ${ }^{\mathrm{b}}$, Jean-Marc MEYNARD ${ }^{\mathrm{c}}$, Antoine MESSÉAN ${ }^{\mathrm{d}}$ \\ ${ }^{a}$ UMR Biologie et Gestion des Adventices, INRA, 17 rue Sully, BP 86510, 21065 Dijon Cedex, France \\ ${ }^{\mathrm{b}}$ Laboratoire de Biostatistique, IURC, 641 avenue Gaston Giraud, 34093 Montpellier, France \\ c UMR d' Agronomie, INRA-INAPG, BP 01, 78850 Thiverval-Grignon, France \\ d INRA Éco-Innov \& CETIOM, BP 01, 78850 Thiverval-Grignon, France
}

(Accepted 25 February 2005)

\begin{abstract}
GENESYS models the effects of regional cropping systems on gene flow between cropped and volunteer rape plants. Its sensitivity to field patterns and cropping system input variables was analysed using Monte Carlo simulations of which the output was analysed by regression trees and linear regressions. The studied simulated output variable was the harvest contamination of conventional crops by genetically modified seeds. The study showed that field characteristics (areas, shapes, distances and orientation) have little effect compared with cropping systems. Gene flow increased with the area of the pollen- and seed-producing field and decreased with the area of the genereceiving field; it increased for elongated vs. square fields and decreased with the distance between fields. The sensitivity analysis identified the distance and time during which cropping systems influence harvest contamination in various field plants. The harvest purity of a cluster of fields was influenced by the cropping history of the fields located less than 200 to $400 \mathrm{~m}$ around the cluster, and of three past years in addition to the ongoing analysed year for major variables such as crop succession or sowing date. The analysis of these major variables pointed to strategies for reducing gene flow, such as increasing the time between successive rape varieties; avoiding high-risk crops such as genetically modified (GM) rape and set-aside in the neighbouring fields for the year preceding the cultivation of a non-GM crop as well as the year during which the non-GM rape is grown; delaying the sowing of non-GM rape.
\end{abstract}

sensitivity analysis / model / cropping system / gene flow / oilseed rape / volunteers / Monte Carlo / input variables / survey plan / GENESYS

\section{INTRODUCTION}

Gene flow in rape is a process taking place both in time and in space, via pollen and seeds, which strongly interacts with the regional cropping system. To assess the impact of introducing genetically modified (GM) crops within the large range of farming systems throughout Europe, single-field experiments or studies are not sufficient. Numerous models have been developed in this domain, but most concentrate on a specific part of the gene flow problem, such as the effects of (a) genetic characteristics (e.g. fitness, mutation rates, self-pollination rates, etc.) on spatio-temporal gene flow (e.g. Lavigne et al., 1998), (b) cropping systems on rape volunteer dynamics (e.g. Pekrun et al., 2005), as well as of (c) distance and environmental conditions on gene dispersal in space, with special reference to pollen dispersal processes (Richter and Seppelt, 2004; Klein et al., 2005).

However, to evaluate the consequences of the introduction of genetically modified rape varieties, it is necessary to take into account all relevant aspects, i.e. cropping systems and genetic characteristics as well as pollen and seed dispersal. Presently, only the model GENESYS-RAPE (Colbach et al., $2001 \mathrm{a}, \mathrm{b}$ ) attempts to synthesise all these aspects. It quantifies the effects of cropping systems (field plan, crop succession and cultivation techniques) on gene flow between rapeseed varieties and volunteers, in time and in space. The model simulates the evolution of demography and genotypic composition of rape plants with time, in each plot of an agricultural area. The model was evaluated by comparing its simulated output to independent field data, thus determining the conditions in which it can be used and the error margin of its predictions (Colbach et al., 2005).

The model can thus now be used to study gene spread in time in a region, and, most importantly, how the characteristics of the farming region and the regional cropping system influence this gene spread. Such a sensitivity analysis leads to the identification and ranking of the main regional cropping factors for gene flow, prerequisite information for proposing changes in regional cropping systems that decrease the progress of the gene in time and in space.

Colbach et al. (2004b) have already tackled part of these questions. They determined the length of time during which the seed bank initially present in a field influences later volunteer populations and the genotypic composition of the rape harvests. They identified the main model input variables and the importance of their retrospective effect on gene flow. They ranked cropping system elements according to their effects on gene

* Corresponding author: colbach@ dijon.inra.fr 
flow, which helps to orientate those developing farming advice towards the most efficient techniques for reducing gene flow. And lastly, they also ranked model parameters and processes according to their effects on gene flow in time and thus identified those biological processes with which the cropping techniques should interact in order to limit gene flow.

However, this study (Colbach et al., 2004b) was limited to gene flow in a single isolated field without any pollen or seed input from neighbouring fields. This is highly unrealistic as these gene vectors have been shown to disperse over large distances and introduce foreign genes into neighbouring fields (Bilsborrow et al., 1994; Lavigne et al., 1998; Champolivier and Messéan, 2002).

It is therefore necessary to extend the study of Colbach et al. (2004b) to a multi-field system. Because of the complexity and the interactions among and between input variables and parameters, it is neither possible to use conventional techniques for sensitivity analysis where each input variable and/or parameter is analysed separately (Daniel, 1973) nor to make all input variables and parameters vary simultaneously. Consequently, the initial method of Colbach et al. (2004b) based on Monte Carlo processes was adapted from a single-field to a multi-field system. This consisted of separating the study into several steps. First, the sensitivity of the model to field patterns was analysed, simulating the contrasted cropping systems identified by Colbach et al. in the various fields. This led to the identification of contrasted field patterns which were used to study the effects of cropping systems in a multi-field system, where the variables to be studied were chosen randomly. Only one of the most important of the numerous model output variables was studied, i.e. the contamination rate of conventional rape harvests by the transgene or any other extraneous gene.

\section{MATERIALS AND METHODS}

\subsection{Presentation of the model GENESYS}

The details of the model are given by Colbach et al. (2001a, b). Only a short description is given here.

The model uses various kinds of input variables:

1. The field plan of the simulated region, comprising both cultivated fields and uncultivated road- and field-margins (hence "borders"). Borders consist of strips of spontaneous vegetation where rape volunteers can appear, producing pollen and seeds that disperse to fields and other borders.

2. The crop grown each year on each simulated field. The model distinguishes transgenic and conventional rape crops, winter cereals, spring cereals and various kinds of set-aside (autumn- or spring-sown, unsown and permanent).

3. The cultivation techniques used to manage each crop and border, comprising stubble breaking, tillage sowing date and density, herbicide spraying, cutting and harvest loss (i.e. seeds lost before or while harvesting rape crops).

4. The genetic variables. The genotypes of the transgenic and conventional rape varieties are $A A$ and $a a$, respectively, where $A$ is the transgene or any dominant allele coding for herbicide-tolerance and $a$ the associated recessive allele.
The genotype therefore determines whether the plants survive herbicide applications, depending on the plant stage and the herbicide active ingredient. In addition, the varieties can differ in pollen and seed production, depending on whether the plants grow in rape crops or in other crops. Self-pollination rates also vary according to genotype.

Furthermore, the user has to determine the initial seed bank on the onset of simulation, with the number of seeds and their genotype proportions in each soil layer.

These input variables influence the annual life cycle of both cultivated and volunteer rape plants which comprises seedlings, adults, flowers, seed production and seed bank left after harvest. The life cycle is simulated for each year in each field and border of the simulated region. For each life stage, both the number of individuals per $\mathrm{m}^{2}$ and the proportion of the three genotypes $A A, A a$ and $a a$ are calculated. The relationships between the life stages depend on whether the plot is a field or a border, on the crop grown in the field and the techniques used to manage the crop or border. Each year, during flowering and seed production, the life cycles of the plots connect, resulting in pollen and seed exchanges between the plots. The importance of these exchanges depends on plot areas and distances.

The main output variables are, for each simulated plot and year, the adult plants (whether cultivated or volunteer), the seed production and the seed bank left after harvest. For each variable, both the number of individuals per $\mathrm{m}^{2}$ and the genotype proportions are calculated.

\subsection{Analysis steps}

Not all input variables need to be studied in the present work. Indeed, during their temporal sensitivity analysis, Colbach et al. (2004b) analysed the effect of the initial seed bank and determined the minimum simulation duration to eliminate its effect. Furthermore, they estimated that for the effect to be negligible for cultivation techniques implemented four or more years before the analysed crop. Despite this considerable decrease, the number of input variables was still too high for a single analysis. Indeed, there are 15 variables per year and field or border for the cropping system and 7 genetic variables.

The multi-field analysis was therefore separated into several parts (Fig. 1):

1. The first step consisted of analysing the effects of individual field characteristics, i.e. plot areas, shapes, orientation and distances, on field-to-field gene flow and the resulting harvest contamination. This step determined how far around the main simulation plots the environment must be simulated. The cropping systems simulated in the plots were the contrasted systems determined by Colbach et al. (2004b), ranging from a high-risk system (with frequent and recent GM crops, little tillage, early sowing of non-GM crops, etc.) to a low-risk system (with rare GM crops, ploughing before non-GM crops, late sowing of non-GM crops, etc.).

2. In the second step, the effect of composite field patterns on gene flow into a given field and the resulting harvest contamination was analysed. A small number of complete field plans was constructed where harvest contamination in the central plot was analysed. These field plans differed in 


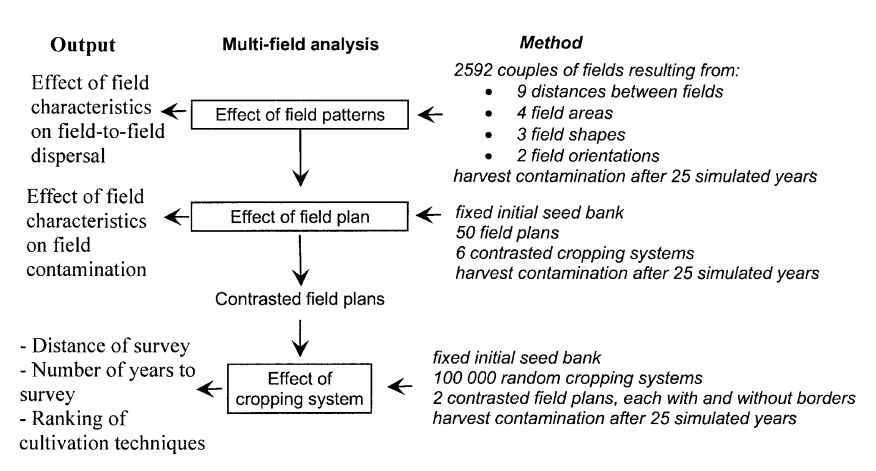

Figure 1. Organisation of the various steps of the multi-field sensitivity analysis of the model to input variables and parameters. Main methods and expected results.

areas and forms for the central plot. Cropping systems were again simulated according to Colbach et al. (2004b).

3 . The results of the first two steps were used to build contrasted field plans for the last part where the effect of cropping systems was studied in interaction with field patterns in order to determine (a) how far away from a central simulation plot and over how many years the past history of the fields must be investigated and (b) how the cultivation techniques are ranked according to their impact on gene flow. Cropping system variables were chosen randomly, according to a uniform distribution. This choice corresponds to a non-informative a priori.

Whatever the analysis step, parameter values were kept constant at the nominal values given by Colbach et al. (2001a, b). The analysed output variable was always the proportion of transgenic seeds in the harvest of the last conventional rape crop (hence "harvest contamination").

\subsection{Choice of input variables}

\subsubsection{The field plan}

The series of plot couples used in the first analysis step was obtained by combining the following factors:

- the distance between the plots which was $0,10,50,100$, $500,1000,1500,2000$ or $3000 \mathrm{~m}$;

- the area of the two plots which was 9, 100, 961 or 10000 $\mathrm{m}^{2}$. These were chosen to comprise both small border and large cultivated fields;

- the form of the two plots which was square, linear with 1m-width or intermediate with length equating three times the width;

- the orientation of the two plots which were either parallel or perpendicular.

In total, there were $9 \cdot 4^{2} \cdot 3^{2} \cdot 2=2592$ couples of plots tested.

In the second step, ten different field patterns were constructed, with the main plot one of the following: $300 \mathrm{~m} \times$ $300 \mathrm{~m}, 100 \mathrm{~m} \times 100 \mathrm{~m}, 10 \mathrm{~m} \times 10 \mathrm{~m}, 1 \mathrm{~m} \times 1000 \mathrm{~m}, 1 \mathrm{~m} \times$ $300 \mathrm{~m}, 1 \mathrm{~m} \times 100 \mathrm{~m}, 1 \mathrm{~m} \times 10 \mathrm{~m}, 10 \mathrm{~m} \times 1000 \mathrm{~m}, 10 \mathrm{~m} \times 300 \mathrm{~m}$ or $100 \mathrm{~m} \times 300 \mathrm{~m}$. The main plot was located at the centre of a $1000 \mathrm{~m} \times 1000 \mathrm{~m}$ region, consisting of identical $100 \mathrm{~m} \times$ $100 \mathrm{~m}$ fields.

For the last step, two contrasted field plans were used, based on the results from the first step. Both only comprised cultivated fields. One of these plans presented a high risk of harvest contamination for the central field, the other a low risk. To investigate the effect of uncultivated borders, such plots were added to the two basic field plans, resulting in two further plans. Several rules were used to add borders: borders were only located along access roads to fields; each field had to be accessible by a road and therefore be adjacent to a border; the number of borders was minimised because farmers would optimise the ratio of cultivated (i.e. fields) and uncultivated (i.e. accessroads with borders) land.

\subsubsection{Initial seed bank and duration of simulation}

Whatever the analysis step, the initial seed bank of all plots was empty. In order to initialise a realistic seed bank for the simulation, the duration of the simulation was 25 years. In the first two steps, only the last year was analysed; in step (3), only the last four simulated years were used for analyses. Consequently, the pre-analysis simulation duration considerably exceeded the time period during which the initial seed bank influences harvest contamination according to the temporal sensitivity analysis (Colbach et al., 2004b).

\subsubsection{Genetic variables}

In all cases, the simulated allele was a dominant $A$; transgenic varieties were $A A$ (which is usually the case for the present GM varieties) and conventional ones $a a$. In the second analysis step, the values determined for the six contrasted cropping systems in the temporal analysis (Colbach et al., 2004b) were used, ranging from high-risk genotypes (low self-pollination of non-GM plants, large pollen emission of GM plants, etc.) to low-risk genotypes (high non-GM self-pollination, low GM pollen emission, etc.). In the last step, the genetic variables were chosen randomly from the $[0,1]$ interval at the beginning of each simulation, according to uniform distribution.

\subsubsection{Crop succession and management}

In the first two analysis steps, the six contrasted cropping systems determined in the temporal analysis were used (Colbach et al., 2004b). They comprised two high-risk systems (maximum+ and maximum-, with frequent genetically modified rape), two intermediate systems (intermediate+ and intermediate-) and two low-risk systems (minimum+ and minimum-, with genetically modified rape only every 10 or 25 years). 7 repetitions were simulated for each cropping system and plot couple or field plan. These 7 repetitions resulted from starting each time with a different crop from the 7-year rotation (e.g. genetically modified rape/winter winter/spring barley/set-aside/ conventional rape/winter wheat/spring barley) simulated in the field plan. The only exception was the plot to be analysed (e.g. central plot in the complete field plan), which was always cultivated with a genetically modified rape variety in the first year (to introduce rape seeds into the simulation) and a conventional rape in the last year. 
Table I. Range of possible values for cultivation techniques, depending on the simulated crop and border.

\begin{tabular}{|c|c|c|c|c|c|c|c|c|c|}
\hline \multirow[t]{2}{*}{ Technique } & \multicolumn{2}{|c|}{ Rapeseed } & \multicolumn{2}{|c|}{ Cereals } & \multicolumn{4}{|c|}{ Set-aside } & \multirow[t]{2}{*}{ Border } \\
\hline & $\begin{array}{l}\text { trans- } \\
\text { genic }\end{array}$ & $\begin{array}{c}\text { conven- } \\
\text { tional }\end{array}$ & winter & spring & $\begin{array}{l}\text { autumn- } \\
\text { sown }\end{array}$ & $\begin{array}{l}\text { spring- } \\
\text { sown }\end{array}$ & unsown & permanent & \\
\hline stubble breaking & $\mathrm{A} / \mathrm{P}$ & $\mathrm{A} / \mathrm{P}$ & $\mathrm{A} / \mathrm{P}$ & $\mathrm{A} / \mathrm{P}$ & $\mathrm{A} / \mathrm{P}$ & $\mathrm{A} / \mathrm{P}$ & A & A & A \\
\hline tillage & $\begin{array}{c}\text { chisel/ } \\
\text { plough/ } \\
\text { no tillage }\end{array}$ & $\begin{array}{c}\text { chisel/ } \\
\text { plough/ } \\
\text { no tillage }\end{array}$ & $\begin{array}{c}\text { chisel/ } \\
\text { plough/ } \\
\text { no tillage }\end{array}$ & $\begin{array}{c}\text { chisel/ } \\
\text { plough/ } \\
\text { no tillage }\end{array}$ & $\begin{array}{c}\text { chisel/ } \\
\text { plough/ } \\
\text { no tillage }\end{array}$ & $\begin{array}{c}\text { chisel/ } \\
\text { plough/ } \\
\text { no tillage }\end{array}$ & $\begin{array}{l}\text { no } \\
\text { tillage }\end{array}$ & $\begin{array}{l}\text { no } \\
\text { tillage }\end{array}$ & $\begin{array}{l}\text { no } \\
\text { tillage }\end{array}$ \\
\hline sowing date & $\begin{array}{l}\text { [1 Aug., } \\
30 \text { Oct.] }\end{array}$ & $\begin{array}{l}\text { [1 Aug., } \\
30 \text { Oct.] }\end{array}$ & $\begin{array}{l}\text { [1 Sept., } \\
30 \text { Nov.] }\end{array}$ & $\begin{array}{l}\text { [1 Feb., } \\
31 \text { May] }\end{array}$ & $\begin{array}{l}\text { [1 Aug., } \\
30 \text { Nov.] }\end{array}$ & $\begin{array}{l}\text { [1 Feb., } \\
31 \text { May] }\end{array}$ & $\begin{array}{c}\text { no } \\
\text { sowing }\end{array}$ & $\begin{array}{c}\text { no } \\
\text { sowing }\end{array}$ & $\begin{array}{c}\text { no } \\
\text { sowing }\end{array}$ \\
\hline sowing density (seeds $/ \mathrm{m}^{2}$ ) & {$[1,150]$} & {$[1,150]$} & {$[1,450]$} & {$[1,450]$} & {$[1,600]$} & {$[1,600]$} & 0 & 0 & 0 \\
\hline 1 st and 2 nd cutting & A & A & A & A & A & A & $\mathrm{A} / \mathrm{P}$ & $\mathrm{A} / \mathrm{P}$ & $\mathrm{A} / \mathrm{P}$ \\
\hline \multicolumn{10}{|c|}{ cutting date (days after flowering onset) } \\
\hline 1st cutting & A & A & A & A & A & A & {$[0,39]$} & {$[0,39]$} & {$[0,39]$} \\
\hline 2nd cutting & A & A & A & A & A & A & {$[0,22]$} & {$[0,22]$} & {$[0,22]$} \\
\hline \multicolumn{10}{|c|}{ herbicides $1 \& 2 \%$ mortality of genotypes } \\
\hline aa & {$[0,100]$} & 0 & {$[0,100]$} & {$[0,100]$} & {$[0,100]$} & {$[0,100]$} & {$[0,100]$} & {$[0,100]$} & {$[0,100]$} \\
\hline $\mathrm{AA}$ and $\mathrm{Aa}$ & 0 & 0 & {$[0,100]$} & {$[0,100]$} & {$[0,100]$} & {$[0,100]$} & {$[0,100]$} & {$[0,100]$} & {$[0,100]$} \\
\hline harvest loss (\%) & {$[0,100]$} & {$[0,100]$} & 100 & 100 & 100 & 100 & 100 & 100 & 100 \\
\hline grazing & A & A & A & A & A & A & A & $\mathrm{A} / \mathrm{P}$ & A \\
\hline
\end{tabular}

$\mathrm{A}=$ absence, $\mathrm{P}=$ presence. For a given crop or border, cultivation techniques are chosen randomly according to a uniform distribution among the possible levels (qualitative variables) or in the range of possible values (quantitative values).

For analysis step (3), for each simulated field and year of a given field plan, the simulated crop was chosen randomly in the list of the eight possible crops given in Section 1.1, according to a multinomial (with equal probabilities) distribution. The only exception was fixed set-aside which could only follow a sown set-aside. The first crop of the central field was again a genetically modified rapeseed and the last one a conventional rape variety. Each year, for each field or border, cultivation techniques were also chosen randomly with uniform probability, but the range of possible variation depended on the simulated crop or border (Tab. I). For instance, a rape crop could be preceded by chisel ploughing, mouldboard ploughing or no tillage and be sown between 1 August and 30 October, whereas borders could never be preceded by tillage and were never sown.

\subsection{Number of simulated repetitions}

In the first two steps, for each field couple or for each field plan, 7 repetitions of the 6 contrasted cropping systems were simulated and the resulting harvest contamination of conventional rape calculated. All input variables were fixed.

In the last step, because cropping variables were chosen at random, it was essential to maximise the number of repetitions to have the largest number of combinations of input variables. Therefore, 200000 simulations were carried out on each of the two field plans, half of the simulations using the field plans with borders and the rest without borders. However, these numbers of repetitions were tiny compared with the enormous number of possible combinations of input variables and/or parameters. As it will never be possible to explore more than a tiny proportion of these combinations, all the analysis steps were repeated with a different set of simulations to test the stability of the observed simulation results.

\subsection{Statistical methods}

\subsubsection{Step 1: effect of field characteristics on field-to-field gene flow}

In the case of the plot couples, the following linear model was used to analyse the harvest contamination of the conventional rape at the 25 th year of simulation:

harvest contamination $=$ constant

+ effect (orientation)

$=\alpha \cdot$ distance

$+\beta_{\text {ea }} \cdot$ area $_{\text {emittingPlot }}+\beta_{\text {ra }} \cdot$ area $_{\text {receivingPlot }}$

$+\chi_{\text {ec }} \cdot$ circumference $_{\text {emittingPlot }}$

$+\chi_{r c} \cdot$ circumference $_{\text {receivingPlot }}$

+ effect (cropping system)

+ interaction (cropping system * initial crop)

+ error. 
For each of the 2592 plot couples, there were two output values, one for each field. Orientation was a qualitative variable with parallel or perpendicular as levels. Cropping system and initial crop were also qualitative variables. The remaining variables were quantitative: the distance $(\mathrm{m})$ between the plot centres, the areas $\left(\mathrm{m}^{2}\right)$ of the receiving and emitting plots, respectively, and the circumference $(\mathrm{m})$ of the plots.

\subsubsection{Step 2: effect of field patterns on harvest contamination}

In the case of the complete field plans, the previous equation was simplified considerably as only the characteristics of the central plot varied:

harvest contamination $=$ constant

$+\alpha \cdot$ area $_{\text {centralPlot }}+\beta \cdot$ circumference $_{\text {centralPlot }}$

+ effect (cropping system)

+ interaction (cropping system $*$ initial crop)

+ error.

Both "raw" and log-transformed output variables were used. If nil values were present for an output variable, the minimum non-zero value was added to all output values to make logtransformation possible. The PROC GLM procedure of SAS was used and only effects significant at alpha $=0.01$ were kept for the final model.

\subsubsection{Step 3: effect of cropping system in interaction with field patterns}

Based on the results of the temporal sensitivity analysis (Colbach et al., 2004b), only the last four simulated years were kept for analysis. The number of input variables was still very large. In the case of the field plans with the least fields ( 35 fields and 21 borders), there was already a total of 2343 variables resulting from 7 genetic variables, $35 \times 4-1$ crop natures (35 fields and four simulated years with the last crop fixed in the central field), 21 border presence indicators, $35 \times 4 \times 12-8$ management variables for the fields ( 35 fields and four simulated years with conventional rape in the central field for which cutting and herbicides were not allowed) and $21 \times 4 \times 6$ for the borders ( 21 borders and four simulated years with only cutting and/or herbicides).

As in the previous work, because of the large number of input variables and interactions, two complementary analysis methods were used: (i) a regression tree, to identify the major input variables - this method is adequate for large data sets with numerous interactions, but tends to neglect minor effects; (ii) a linear model applied to a reduced set of input variables, to quantify and rank both major and minor explicative variables.

A regression tree is the collection of many rules displayed in the form of a binary tree. The tree is grown by binary recursive partitioning using the response (here harvest contamination) and choosing splits from the input variables in order to minimise heterogeneity in the resulting nodes which is measured by deviance. Numeric variables are divided into $X<\mathrm{a}$ and $\mathrm{X}>\mathrm{a}$; the levels of qualitative variables are divided into two non-empty groups. The split which maximises the reduction in impurity is chosen, the data set split and the process repeated. Splitting continues until the deviance of the terminal nodes decreases below a fixed threshold, usually 0.01 , or until the number of observations in a node falls below a pre-defined threshold.

In the present case, the combination of the large number of input variables and of repetitions made it impossible to use this method on the complete data set using all input variables simultaneously. Therefore, the data sets corresponding to each of two field plans were split into the data corresponding to the simulations with and without borders, respectively. Furthermore, the input variables were separated into various groups, i.e. genetic variables, crop succession variables, tillage variables, etc. Each sub-data set was analysed separately with each sub-group of input variables, using a minimum deviance decreased to 0.005 (instead of the standard value 0.01 ). In the case of the low-risk field plan where the number of plots was large, the data sets were further separated into sub-sets differing in when the most recent genetically modified rape in the central field was cultivated, i.e. 1, 2 to 3 or 4 and more years previously.

The input variables selected for each field plan during segmentation were then introduced as input variables into a linear regression model. As regression trees tend to select only those variables with dominant effects, several other variables were added to this first selection in order not to neglect any minor but still significant effects. These comprised all genetic variables eliminated during segmentation. Furthermore, if, for a given management technique, only the variable for the years 0 and 1 (corresponding to the analysed crop and its previous crop) were selected during segmentation, then the variable for the year 2 (corresponding to the pre-previous crop) was also added to the linear model. Similarly, if only the variable for the central analysed plot was selected, then the variables for its immediately neighbouring plots were also added. Furthermore, all data on border presence and management were added again as the separate analyses of the field plans with and without borders did not allow any correct evaluation of these variables.

If all input variables were selected, the tested linear model would be:

harvest pollution $_{0, c f}=$ constant

$+\alpha_{\text {ryrc }} \cdot$ relative yield rape crops

$+\alpha_{\text {rye }} \cdot$ relative yield elsewhere

$+\alpha_{\text {rprc }} \cdot$ relative pollen emission ${ }_{\text {rape crops }}$

$+\alpha_{\text {rpe }} \cdot$ relative pollen emission elsewhere

$+\beta_{G M R} \cdot$ years since last GMrape

$+\beta_{N G M R} \cdot$ years since last NGMrape

$+\sum_{\substack{p=1 \\ p \neq c f}}^{N F} \sum_{y=0}^{3} \chi_{y, p} \cdot \operatorname{crop}_{y, p}$

$+\sum_{p=1}^{N F} \sum_{y=0}^{3} \sum_{q=1}^{12} \delta_{y, p, q} \cdot$ crop $_{y, p}$ cultivation technique $y, p, q$

$+\sum_{p=1}^{N B} \chi_{y, p} \cdot$ border $_{p}$

$+\sum_{p=1}^{N B} \sum_{q=1}^{6} \delta_{p, q}$ cultivation technique ${ }_{p, q}+$ error. 
Year 0 is the last simulated year and $c f$ the central field for which the harvest contamination of conventional rape was analysed. $\alpha, \beta, \chi_{y, p}$ and $\delta_{y, p, q}$ are regression parameters. The $\alpha$ parameters depended on the nature of the associated genetic input variable, $\chi_{y, p}$, on the simulated year $y$ (years before the analysed year 0 ) and the plot $p, \delta_{y, p, q}$ on the year, the plot and the simulated cultivation technique. There was a total of $N F$ fields and $N B$ borders. If the analysed harvest contamination had been simulated in a field plan with borders, the variable border $_{p}$ had the value 1 , otherwise 0 . Various combinations of $\sum_{=1}^{N F} \sum_{y=0}^{3} \sum_{q=1}^{12} \delta_{y, p, q} \cdot$ crop $_{y}, \cdot$ cultivation technique $y, p, q$ were constants and therefore not introduced into the regression model. For instance, there could be no cutting for rapeseed and no tillage for unsown set-aside. Furthermore, management of borders was reduced to herbicide applications and cutting. The effects of cultivation techniques were only studied in interaction with crop nature as they strongly depended on the crop where the techniques were used.

Some of the input variables were quantitative (e.g. sowing density), others were qualitative variables and transformed into quantitative variables using Boolean coding. This approach does not require any transformation of variables with only two levels (e.g. stubble breaking, presence of 1 st cutting). The qualitative variables with more than two levels were replaced by a series of dummy variables with only two levels each. For instance, the variable tillage with the three levels chisel, mouldboard ploughing and no tillage was transformed into two distinct variables equating $(1,0)$ for chisel, $(0,1)$ for mouldboard ploughing and $(0,0)$ if no tillage.

The reason for transforming qualitative into quantitative variables was to make possible the use of the REG procedure of SAS which only accepts quantitative input. The STEPWISE option of this procedure successively introduces the most important input variables into a regression model. Effects were only entered if they were significant at alpha $=0.05$; in the final model, only effects significant at alpha $=0.01$ were kept. The advantage of the REG vs. the GLM procedure is the automatic addition and removal of input variables. The automatic aspect is crucial because of the large number of input variables. The regression tree was carried out, using the $\mathrm{S}+$ tree() function.

Whatever the analysis step, all equations were also used with a log-transformed output variable. Only the models with the highest $r^{2}$ are presented here. The log-transformation was preferred to other transformations used for analysing proportions as it does not change the unit of the analysed variable. The symmetry and the normality of the distribution of residuals of the various models was checked; the graphs showed approximately normal distribution centred on zero; the Skewness value was usually close to zero, thus indicating a symmetric distribution (results not shown).

\section{RESULTS AND DISCUSSION}

\subsection{Effect of field patterns (steps 1 and 2)}

Field-to-field gene (step 1) dispersal and the resulting harvest contamination decreased with the distance between the
Table II. Effects of field patterns and cropping systems on harvest contamination of conventional rape crops. Results of linear models [1] and [2].

\begin{tabular}{|c|c|c|c|}
\hline \multirow[t]{3}{*}{ Explicative variable } & \multicolumn{3}{|c|}{ Field pattern } \\
\hline & \multicolumn{2}{|c|}{ Isolated plot couples } & Complete field plans \\
\hline & Estimate & Partial $r^{2}$ & Estimate $\quad$ Partial $r^{2}$ \\
\hline constant & 41.5 & & 36.4 \\
\hline distance & $-1.25 \times 10^{-4}$ & $7.76 \times 10^{-5}$ & not tested \\
\hline orientation & & $3.2 \times 10^{-6}$ & not tested \\
\hline parallel & $5.15 \times 10^{-2}$ & & \\
\hline perpendicular & 0 & & \\
\hline
\end{tabular}

\section{area of}

$\begin{array}{lccc}\text { emitting plot } & 3.53 \times 10^{-6} & 3.6 \times 10^{-7} & \text { not tested } \\ \text { receiving plot } & -8.62 \times 10^{-6} & 2.4 \times 10^{-7} & -1.23 \times 10^{-5} 2.9 \times 10^{-5}\end{array}$

circumference of

$\begin{array}{lrrr}\text { emitting plot } & -2.14 \times 10^{-6} & 4.8 \times 10^{-7} & \text { not tested } \\ \text { receiving plot } \times \text { area } & & 1.7 \times 10^{-4} & 1.01 \times 10^{-4} 6.4 \times 10^{-4} \\ 9 & -1.97 \times 10^{-2} & \\ 100 & -2.16 \times 10^{-3} & \\ 961 & -2.70 \times 10^{-4} & \\ 10000 & -2.49 \times 10^{-5}\end{array}$

cropping system

0.992

0.984

maximum+

41.9

36.5

maximum-

40.8

35.6

intermediate+

30.3

26.0

intermediate-

30.1

26.0

minimum+

19.1

16.9

minimum-

0

0

cropping system $\times$ not detailed $3.90 \times 10^{-3}$ not detailed $1.03 \times 10^{-2}$ initial crop

Total $\mathrm{r}^{2}$

0.996

0.995

Only terms significant at alpha $=0.01$ were kept in the final models. Output variables had been $\log$-transformed. Partial $r^{2}$ was the contribution of a given variable in the final model consisting of all significant variables.

field boundaries (Tab. II). Harvest contamination increased with the area of the emitting plot and decreased with the area of the receiving plot. The shapes of the plots were also very important: contamination decreased with the circumferences of the fields, i.e. elongated plots both dispersed and received more pollen than square plots. The orientation of the fields also influenced gene flow, which was higher for parallel vs. perpendicular plots. However, the main factor was the cropping system, which explained almost all the variability in harvest contamination (partial $\mathrm{r}^{2}$ close to total $\mathrm{r}^{2}$ ).

The results were similar when analysing harvest contamination of a receiving field located in a continuously cropped region (step 2), except that the characteristics of the emitting 


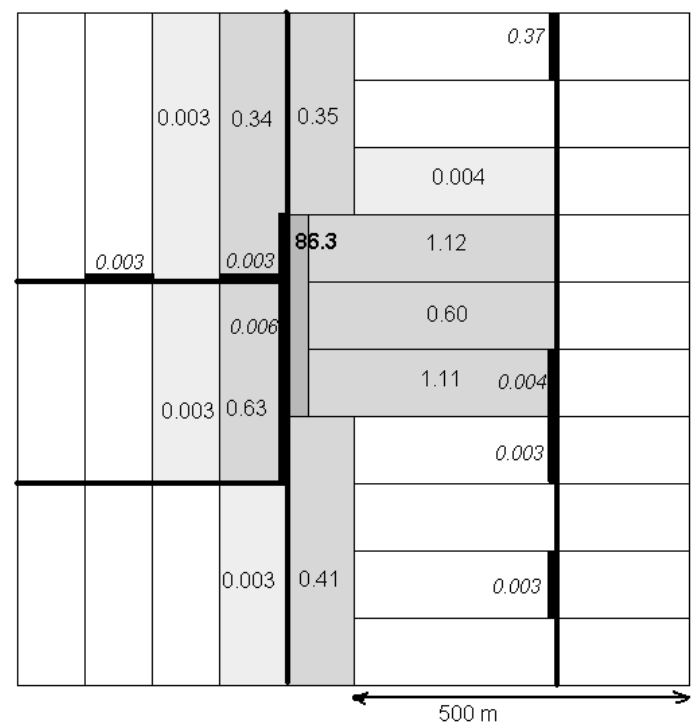

Figure 2. Contributions (\%) of the various fields (rectangles, nonitalic script) and borders (double black lines, italic script) of the highrisk field plan to total $\mathrm{r}^{2}$ to explain harvest contamination of conventional rape in the central plot (dark grey rectangle, bold script). Significant borders are shown by triple black lines; significant fields by different shades of grey. Example of data set 1 .

plots were not analysed. Again, the cropping system effect explained almost the entire variability of the harvest contamination of the central field (Tab. II). This contamination also decreased with the area of the central field. In contrast to step 1, contamination increased though for elongated vs. square plots (positive correlation with circumference).

\subsection{Construction of contrasted field plans}

Based on the previous results, the high-risk field plan consisted of a small, elongated central field (considered as the receiving field) and of large elongated surrounding fields (emitting fields). Conversely, the central field of the low-risk field plan was large and square and its neighbours small and square (Figs. 2, 3). Both field plans were duplicated to add borders. The plans were $1000 \mathrm{~m}$ by $1000 \mathrm{~m}$ large.

\subsection{Effect of cropping system on harvest contamination of conventional rape (step 3)}

\subsubsection{Regression trees}

Table III shows the variables selected by the regression tree for their effects on harvest contamination of the conventional rape crop in the central field of the various field plans. For a given field plan, there were no differences between the simulations with and without borders, respectively. Neither were there any differences between the replicated data sets for a given field plan. Only the input variables describing the cropping system of the central analysed fields were selected during

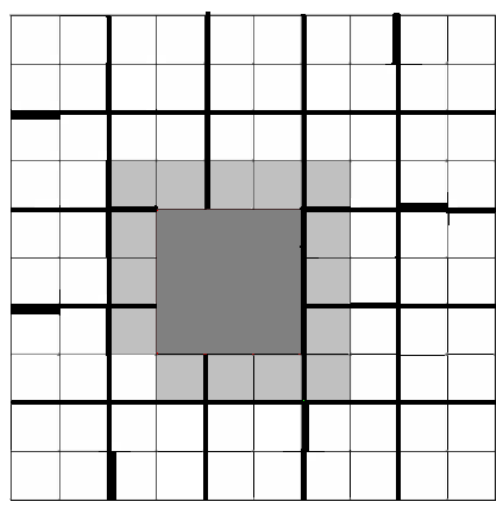

Figure 3. Fields (light grey) and borders (triple black lines) of which the management significantly influences the harvest contamination of conventional rape in the central analysed field (dark grey) in the low-risk field plan.

Table III. Cropping system input variables of central fields selected with the regression tree carried out for the harvest contamination of conventional rape in the field plans without borders. Results of data sets of 100000 simulations per field plan resulting from GENESYS.

\begin{tabular}{|c|c|c|c|c|c|c|}
\hline \multirow[t]{2}{*}{ Analysed variable group } & \multicolumn{6}{|c|}{ Field plan } \\
\hline & \multicolumn{3}{|c|}{ "High-risk" } & \multicolumn{3}{|c|}{ "Low-risk" } \\
\hline years since last GM rape ${ }^{1}$ & \multicolumn{3}{|c|}{$\mathrm{x}$} & \multicolumn{3}{|c|}{$\mathrm{x}$} \\
\hline & \multicolumn{3}{|c|}{$\begin{array}{c}\text { Past effects for } \\
\text { years }^{2}\end{array}$} & \multicolumn{3}{|c|}{$\begin{array}{l}\text { Past effects for } \\
\text { years }\end{array}$} \\
\hline & 0 & 1 & 2 & 0 & 1 & 2 \\
\hline crop & 3 & $\mathrm{x}$ & $\mathrm{x}$ & & $\mathrm{x}$ & $\mathrm{x}$ \\
\hline \multicolumn{7}{|l|}{ stubble breaking } \\
\hline tillage & $\mathrm{x}$ & & & $\mathrm{x}$ & & \\
\hline sowing date & $\mathrm{x}$ & $\mathrm{x}$ & & $\mathrm{x}$ & $\mathrm{x}$ & \\
\hline sowing density & $\mathrm{x}$ & $\mathrm{x}$ & & $\mathrm{x}$ & $\mathrm{x}$ & \\
\hline $\begin{array}{l}\text { herbicide 1: mortality of: } \\
\text { GM plants }\end{array}$ & & $\mathrm{x}$ & & & & \\
\hline non-GM plants & & $\mathrm{x}$ & & & & $\mathrm{x}$ \\
\hline $\begin{array}{l}\text { herbicide } 2 \text { : mortality of: } \\
\text { GM plants }\end{array}$ & & $\mathrm{x}$ & & & & $\mathrm{x}$ \\
\hline non-GM plants & & $\mathrm{x}$ & & & $\mathrm{x}$ & $\mathrm{x}$ \\
\hline 1 st cutting & & $\mathrm{x}$ & & & $\mathrm{x}$ & \\
\hline \multicolumn{7}{|l|}{ 2nd cutting } \\
\hline harvest loss & & & & & $\mathrm{x}$ & $\mathrm{x}$ \\
\hline
\end{tabular}

${ }^{1} \mathrm{GM}=$ genetically modified, non-GM = conventional non-genetically modified.

${ }^{2} 0=$ cultivation techniques applied to the analysed conventional rape crop; $\mathrm{i}=$ techniques applied to the crop grown $i$ years before the analysed

${ }^{3}$ Shaded cells indicate variables that were constant for the crop $\times$ technique combination and not used during segmentation. 
the segmentation tree; none of the variables of the neighbouring fields was important enough to be selected.

\subsubsection{High-risk field plan}

For the linear model applied to the high-risk field plan, total explained variability $\left(\mathrm{r}^{2}\right)$ of the contamination of the conventional rape harvest of the central field by equation (4) was only 0.62 (data set 1). The largest part of this variability (Fig. 2) was explained by the history of the analysed central field $(86.3 \%$ of the total $\mathrm{r}^{2}$, resulting from dividing the partial $\mathrm{r}^{2}$ by the total $\mathrm{r}^{2}$ ) and a small part by its immediately neighbouring fields (4.7\%). Among the remaining fields, only those next to the neighbouring fields and located less than $200 \mathrm{~m}$ from the central field were significant but they only had a very slight effect $(0.01 \%)$. Borders contributed a little more $(0.4 \%)$. The significant borders were located both inside the 200 -m radius and outside up to $425 \mathrm{~m}$ from the central field. Despite their small area, some of the borders influenced the harvest contamination in the central field more than the non-neighbouring fields. Besides the existence of the borders in the specific locations, the fact whether herbicides were applied to these borders during the analysed year was crucial. Harvest contamination in the central field increased with increasing conventional volunteer mortality after spring herbicides (results not shown). The remaining part of the $\mathrm{r}^{2}$ was related to the intercept $(8.8 \%)$.

The effects of the cropping history of the analysed central field are presented in Table IV. The various cultivation techniques were ranked according to their part in explaining the variability in harvest contamination, and their effect analysed separately for each year and crop. This analysis showed that the sowing date of the analysed conventional rape crop and, to a lesser degree, the dates of the previous crops, were the overall dominant factors (Tab. IVB). Sowing dates determine the emergence rates of volunteers in the crops and their subsequent flowering dates. Generally, the analysis showed that the later the sowing, the less harvest contamination. The other dominant factor was the sowing density of the analysed rape: the higher its density, the lower the harvest contamination.

Another factor explaining a large part of variability in harvest contamination was the crop succession, which was analysed via two types of variables: the time since the last genetically modified rape or the last non-GM rape (Tab. IVA), as well as the absence or presence of the remaining crops (Tab. IVB). Harvest contamination decreased enormously when the time since the last GM crop increased. In addition, the presence during the previous three years of autumn-sown crops and set-asides as well as unsown set-aside, where rape volunteers are most frequent, increased harvest contamination. In contrast, spring-sown crops and set-asides as well as permanent set-aside helped to decrease it. Tillage, which buries or excavates the seeds produced during the previous crops, was crucial. Tillage vs. no tillage before conventional rape considerably decreased harvest contamination, and mouldboard ploughing was the most efficient tillage mode. Before the other crops, any tillage operation led to an increase in harvest contamination in the later conventional rape.

A single cutting in previous set-asides, which delays flowering, considerably decreased the output variable. Harvest loss of rape crops during the previous two years significantly increased harvest contamination. Herbicide applications at seedling and adult stages during the previous two years were of medium importance and their effect depended on the rape genotype: harvest contamination decreased with increasing mortality rates of transgenic volunteers but increased when conventional volunteers were eliminated.

Stubble breaking before the analysed conventional rape, which decreases seed bank loss after harvest, slightly increases harvest contamination. A second cutting of previous set-asides, which limits seed production, had next to no impact except slightly increasing later harvest contamination. Grazing in a previous permanent set-aside helped to decrease harvest contamination. Cutting dates had no effect.

The effects of the cropping history of the neighbouring fields are presented in Table V. Techniques were ranked according to the number of fields for which they were significant. The general ranking and the effects of the cropping system components observed in the neighbouring fields was similar to those described for the analysed central field. A few points should, however, be mentioned specifically. The most important sowing date was that of genetically modified rape, both during the year of analysis and the previous years. The later its sowing, the higher the related harvest contamination in the conventional rape in the central field. Similarly, its sowing density during the analysed year was also crucial. Cutting and herbicides, which determine the date, the size and the genotype proportions of the pollen cloud migrating from the surrounding fields to the central field were more important than in the central field. However, a second cutting, which always takes place after the end of the flowering of rape fields, had no impact during the analysed year. Moreover, tillage also had less impact on the neighbouring fields. The remaining fields had no effect, except for a slight influence of the time since the last rape crops in one or two fields (data not shown).

As said above, no pattern could be detected for the distribution of the significant borders. The effect of their herbicide treatments was only significant for the ongoing analysed year and not in all significant borders. For some, only the absence or presence of a border was significant at a specific location and therefore the every-year possibility of pollen and seed production with low competition. The way the herbicides acted were identical to that observed in fields: harvest contamination in the central field increased with increasing herbicide efficiency on conventional phenotypes, whereas the opposite was true for efficiency on transgenic types.

No genetic variable was significant.

\subsubsection{Low-risk field plan}

The results obtained on the low-risk field plan were very similar. Only the main differences will be presented here. Harvest contamination of the central field was even more related to the management of this field than in the high-risk field plan, as $98.3 \%$ of the variability of the harvest contamination were explained by cropping system variables of the central field. Only the immediately neighbouring fields influenced the central harvest contamination (Fig. 3) and their contribution was only $1.5 \%$ of total $\mathrm{r}^{2}$. Similarly, the contribution of border presence and management was also lower than in the high-risk field 

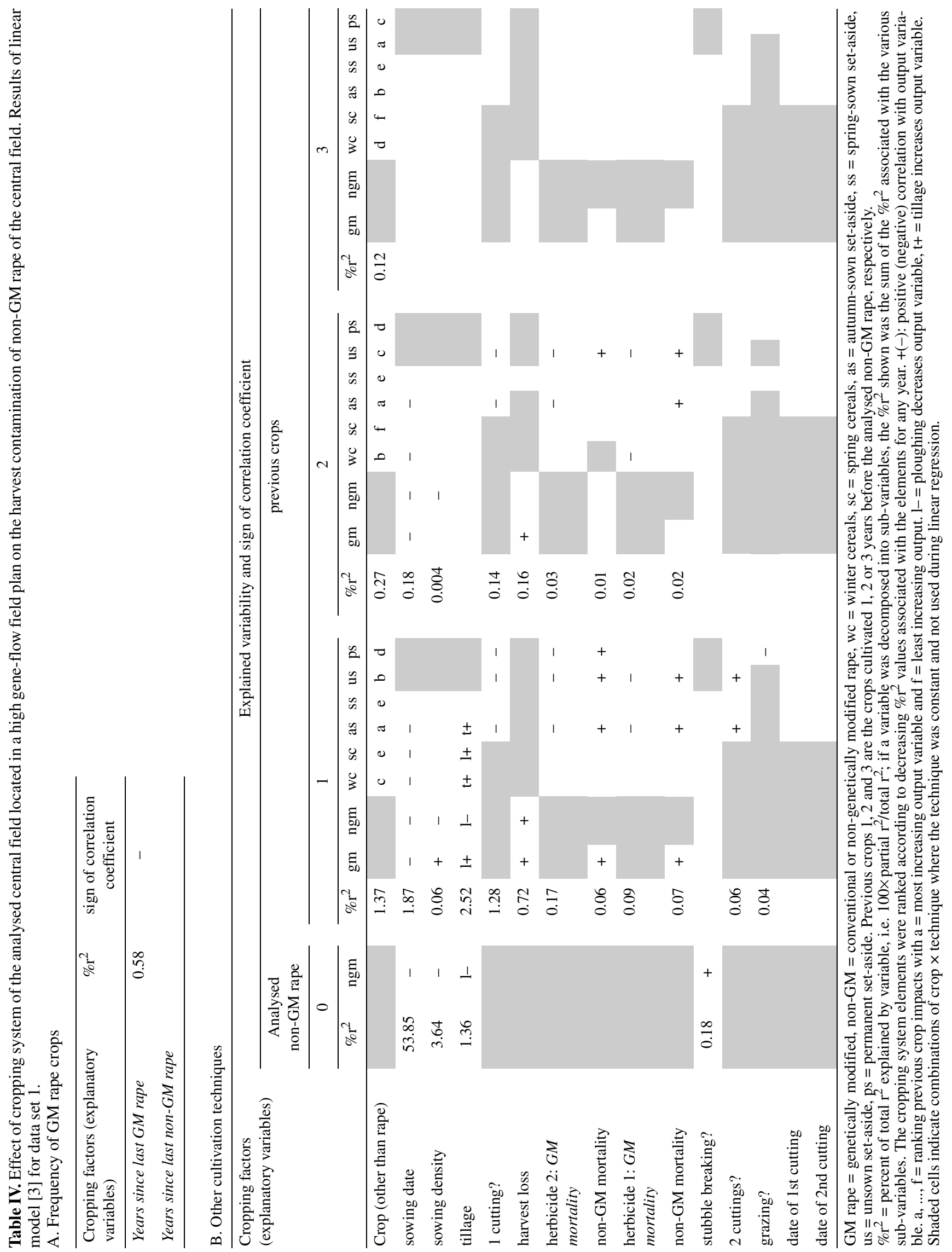

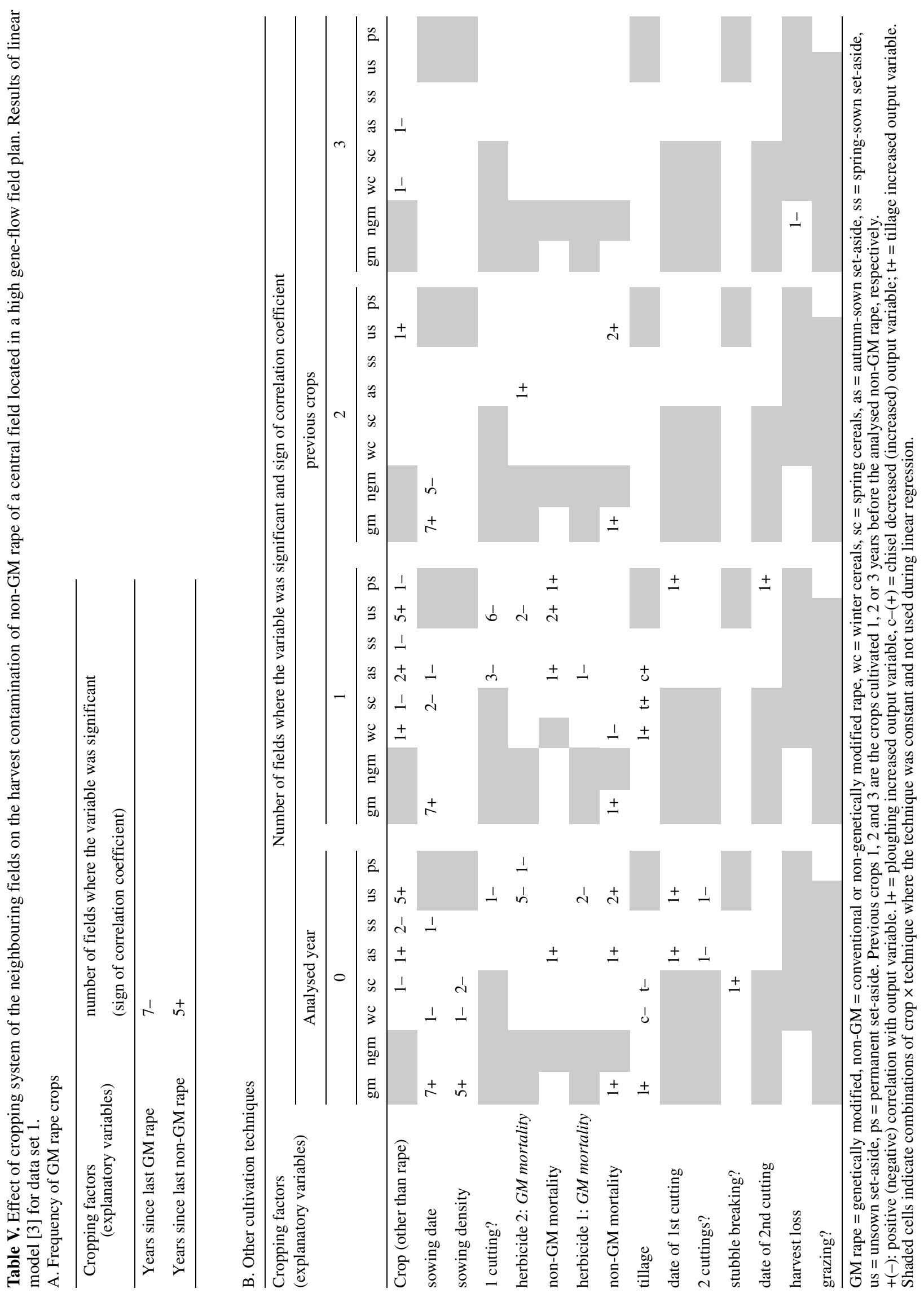
plan $(0.1 \%)$. The borders which influenced the central field were not those located closest to the analysed field, but were scattered without any apparent pattern in the simulated region.

The cropping system effects were identical to those observed for the high-risk field plan but their degree of significance varied (results not shown). In the case of the central analysed field, several techniques presented shorter-term effects; e.g. sowing density was not significant for the -2 crop and single cutting not at all. In contrast, harvest loss of genetically modified rape and mortality of transgenic volunteers for spring herbicides in autumn-sown set-aside were also significant for year -3 .

The same tendencies were observed for the cropping system variables of the neighbouring fields. Variables such as sowing density, single or double cutting and cutting dates were not significant at all, whereas tillage saw its influence reduced to the previous crop only. On the other hand, mortality of conventional volunteers for autumn herbicides was significant even for year -3 .

\subsubsection{Stability of results between data sets}

Concerning fields, the results were nearly identical for the second data set (results not shown). The same fields presented a significant effect on the central harvest contamination and the same cultivation techniques were significant for the same length of time. In some cases, a technique might be significant for one more crop in one data set, e.g. tillage was significant for all rape crops as well as all autumn-sown crops and setasides of year -1 in data set 1 , and in the case of data set 2 , it was also significant for spring-sown crops. The situation was, however, very different for borders. The location of the significant borders changed considerably between data sets and no significant pattern of their distribution could be identified.

\subsection{Quality of the sensitivity analysis}

The methodology developed by Colbach et al. (2004b) for the temporal sensitivity analysis of GENESYS could also be used satisfactorily for the spatial analysis. The step-by-step procedure made it possible to study the effects of the numerous input variables while still taking into account possible interactions. This avoided concluding on the effects of a given input variable while only using one set of values for the remaining input variables, which has frequently been done in previous sensitivity analyses (Hamby, 1994).

When looking at the field histories, the results varied little between the analysed data sets, and this despite the low number of simulated repetitions compared with the huge number of possible combinations of input variables. However, the situation was very different for the border effects, for which the results varied greatly between data sets and no underlying pattern could be identified. Compared with the fields, the area of the borders was tiny and the number and range of cultivation techniques limited. The resulting influence on harvest contamination was probably too small to be adequately studied with the number of simulated repetitions used in the present analysis.

Therefore, even if the present analysis cannot conclude satisfactorily on the effect of borders, the applied method was adequate for field histories. In that case, the number of simulated repetitions and the chosen methods, mainly the combination of segmentation and linear model in the third analysis step, constituted a satisfactory and easy-to-apply compromise when analysing a large number of variables.

In addition, the previous discussion of the analysis quality referred only to how well the present methodology analysed the functioning of the GENESYS model; it did not reflect on how well GENESYS represents gene flow in the agricultural reality. This study was presented in a different paper (Colbach et al., 2005) and those results must be kept in mind when analysing the present results on the effects of field patterns and cropping systems.

\subsection{Field patterns}

In the first analysis step, all the effects of field patterns observed in the present analysis were logical results considering the individual pollen (Klein, 2000) and seed dispersal functions (Colbach et al., 2001b) used by GENESYS after quadruple integration to sum dispersal between all points of two plots (Colbach et al., 2001b). Both functions distribute most of the pollen and seeds close to the source plant and the probability of dispersal then decreases sharply with the distance to the source plant. This distance effect explains why field-to-field gene flow and the resulting harvest contamination decreases with the distance between the fields. The effect of field orientation also hides a distance effect: in the case of parallel plots, there are shorter distances than in the case of perpendicular plots. The same applies for explaining the effects of field shapes: in the case of elongated plots (with high circumferences), the distances to locations in neighbouring fields are larger than in the case of square plots. When, however, the receiving field is entirely surrounded by cultivated fields as in step 2, the situation is very different. The more elongated the analysed field, the more vulnerable it becomes to gene inflow. Indeed, in a square field, the central points are further away from any neighbouring fields than in an elongated field and thus less sensitive to pollen and seed import. In an elongated field, more points are close to outside fields.

The effect of plot areas is different. In the case of the pollenor seed-emitting plot, an increase in plot area leads to an increase in production area, thus explaining the increase in dispersal. The opposite is true for the receiving plot: the larger its area, the more thinly the immigrating pollen or seeds are distributed over the plot and the smaller the dispersal to a given plot location.

Both the first steps showed, however, that, despite its importance for the basic pollen and seed dispersal, the field pattern had only a little effect on the harvest contamination of nongenetically modified rape crops resulting from gene flow. The dominant factor was the cropping system, both in the field where the conventional crop was cultivated and in the surrounding fields. Consequently, when surveying a region to obtain input data for GENESYS, it appears to be much more important to get accurate information on cropping systems than on the precise delimitation of the surveyed fields.

\subsection{Effect of field pattern on cropping system impact}

The analysis of the effects of field histories in the two field plans used in the last step showed that the construction of field 
plans with two contrasted levels of gene flow had indeed been achieved. In the "high-risk" field pattern, the distance at which field history influenced the harvest contamination of the central field was approximately double the equivalent distance in the "low-risk" plan, thus showing that gene flow had been more important in the high-risk plan. Similarly, the past history of the neighbouring fields was significant for much longer in the high-risk plan. In contrast, in the low-risk plan, the cropping history of the central analysed field was much more important and the effects of the techniques lasted longer than in the highrisk plan.

This tendency was confirmed by the comparison of the present results with those obtained during the temporal sensitivity analysis (Colbach et al., 2004b). Again, most of the effects of the cropping system were identical for the isolated field used in the temporal study. However, many effects lasted longer when the analysed field was isolated and no pollen or seeds were imported from the surrounding area. This was, for instance, the case for stubble breaking and mortality rates for spring herbicide which were all significant up to year -3 .

There were a few differences in cultivation techniques between the temporal and the spatial analyses. In the spatial analysis, sowing date presented the main effect, in contrast to the temporal analysis where crop succession was the dominant factor. This is consistent with the underlying biological and agronomic processes. Indeed, crop succession determines seed production and survival of rape volunteers over the years and thus the only path of gene flow for the isolated field. When the analysed field is surrounded by other fields, gene flow via pollen becomes a major process. This depends on the flowering dates of both cultivated and volunteer rape plants, which are again determined by the crop sowing dates.

This also explains why stubble breaking had such a small impact in the spatial analysis. Stubble breaking plays a major role in seed survival and dormancy and was thus important for the isolated field but not for the encircled field.

\subsection{Effect of neighbouring cropping systems}

Most of the cropping system elements presented the same effects and ranking, whether on the analysed field or on neighbouring fields. There were, though, several key differences. Techniques influencing flowering dates such as the sowing date of neighbouring genetically modified rape, and the presence of a first cutting in set-aside and its date were more important in neighbouring plots. A first cutting destroys all existing ramifications, but new ramifications are produced by the plants which then flower later. Moreover, factors determining the ratio of transgenic to non-transgenic plants and therefore the composition of the pollen cloud immigrating into the central field also presented a larger impact in the neighbouring fields, such as herbicide efficiencies. In contrast, techniques determining only the absolute value of seed production, without reference to flowering dates or genotype, were less important in the neighbouring fields. These were, for instance, tillage, which determines the amount of seeds close enough to the soil surface for emergence or second cutting in set-aside, which reduces volunteer seed production considerably. The change in flowering dates due to the second cutting did not have any effect on pollen flow to a neighbouring rape crop as the cultivated rape had finished flowering by the time the volunteer rape started to reflower after the first cutting.

\subsection{Effect of borders}

As said above, the methodology of the present study and more particularly, the number of simulated repetitions, was not totally adequate to evaluate the effects of borders, whether presence/absence or management. The analysis showed, however, that borders presented an important effect as they significantly influenced harvest contamination in faraway fields, and this despite the small area of the borders relative to the field areas. The identified herbicide effects were consistent with those observed in borders and with the knowledge on the underlying biological processes.

Consequently, the integration of the borders into GENESYS was essential. However, during the evaluation of the model (Colbach et al., 2005), volunteer densities observed along borders in a farming region were compared with simulated border densities. This comparison showed that the model did not adequately predict absolute values for these densities, even if the various situations were ranked correctly by the model. The importance of borders for the functioning of GENESYS must therefore be reanalysed after the model has been improved and predicts the border volunteers better.

\subsection{Effect of rape varieties}

In the present study, none of the characteristics used by GENESYS to differentiate rape varieties presented a significant effect on harvest contamination. In contrast, the previous temporal study (Colbach et al., 2004b) showed all varietal variables to significantly influence harvest contamination. The most important of these were the self-pollination rate of $a a$ genotypes as well as the relative seed and pollen production of transgenic vs. conventional phenotypes in rape fields. The absence of significant genotype effects in the present study does not rule out any actual effect of these variables. But it appeared that the relative behaviour of the genetically modified and conventional varieties is of little importance compared with cropping system effects when the spatial gene flow dominates the temporal flow. In contrast, when gene immigration into the field is negligible as in the temporal study, the differences in varietal behaviour become crucial and reflect the competition of the various genotypes and phenotypes for space, nutrients, etc. during growth, development and seed production as well as fecundable flowers during pollination. This is consistent with the simulation results produced with an amended GENESYS version containing further genes coding for plant height, male sterility and flower morphology (Fargue, 2002; Fargue et al., 2004). These also showed that genotype and phenotype differences presented the strongest effects in the case of temporal vs. spatial gene flow.

\subsection{Determination of pertinent changes in cropping systems}

The determination of the distance at which neighbouring fields influence a given field should be based on the results 
observed for the high-risk field plan where the effects of the neighbouring fields were most perceptible. Consequently, the distance of influence would be approximately $200 \mathrm{~m}$, thus requiring a buffer space of $200 \mathrm{~m}$ around the non-GM fields in agricultural regions. However, the evaluation of GENESYS (Colbach et al., 2005) comparing simulations with independent field observations showed the model to underestimate gene flow in space, probably because the tail of the pollen dispersal function is too light (Klein et al., 2005). In the evaluation study, the observed dispersal distance appeared to be approximately double the simulated dispersal distance. If possible, it would therefore be advisable to increase the buffer distance to $400 \mathrm{~m}$ in order to avoid neglecting even minor effects while awaiting new simulations with an improved GENESYS version comprising a heavy-tail dispersal pollen function.

The distance at which the existence and management of borders influence the harvest quality of a given field could not be determined satisfactorily in the present study where the significant borders were located both among the significant fields and further away, and no stable pattern could be discerned on the various analysed data sets. A cautious approach would fix the distance at which border management has to be taken into account, at the distance where the furthest border was located, i.e. approximately $400 \mathrm{~m}$ in the present analysis. However, the management of borders depends on stakeholders as different as public road authorities and farmers, who have diverse constraints and objectives. As a compromise, border management could be supervised as far as the neighbouring fields, especially as it is easier to evaluate and design management strategies for a border in combination with its neighbouring field.

The results observed for the high-risk field plan and presented in Tables IV and V can be assimilated to a "worst-case" scenario for the spatial extent of the effect of regional cropping systems on a given field. However, to determine the temporal span of influence of the cropping system, the "worst-case" scenario to analyse is the single-field situation studied by Colbach et al. (2004b). Consequently, the management of the current year can be expected to influence future non-GM harvest contamination for approximately three further years. Conversely, when determining the optimal cultivation techniques for an ongoing year, the farmer needs to take into account the management of the previous three years.

The ranking of the cropping system elements established with the sensitivity analysis shows that the most efficient way to reduce harvest contamination would be to modify crop succession by maximising the number of years between two different rape varieties and by avoiding autumn-sown and unsown set-aside in the rotation of the field where conventional rape is to be grown. Similarly, the neighbouring farmers should avoid these high-risk crops during the year where the conventional rape is grown, but also during the preceding years. Furthermore, the spatial analysis also shows that regional crop succession is not the only factor, as rape sowing dates were revealed to be major determinants for harvest contamination of conventional rape. The constraints for both the conventional farmer and his neighbours are far-reaching both in time and in space and can therefore not be determined solely by field experiments.
The results of the present sensitivity analysis can, however, not be used directly for developing farming advice. They only present a ranking of cultivation techniques and show that changes in sowing dates and densities are much more efficient at influencing harvest contamination than changes in cutting dates, for instance. To develop new cropping systems that limit gene flow, it is necessary to first evaluate diverse existing farming systems ranging from large-field intensive to small-field organic farms. For each of these situations changes in cropping systems should then be simulated, chosen according to the ranking of impact determined in the present study. GENESYS is already used for this kind of procedure for evaluating and developing cropping systems limiting harvest contamination in rape food and seed harvests (Angevin et al., 2002; Colbach et al., 2004a). Furthermore, advice would strongly depend on the problem encountered by the farmer; indeed, the optimal cropping system for reducing harvest contamination is not the necessary one adapted to limit the appearance of rape volunteers in cereals (Colbach et al., 2004b). Studies must therefore be specific to the analysed farming system and its related problem.

\subsection{Rules for the use of GENESYS}

Therefore, in addition to establishing the distance and time of influence of cropping system elements, the present sensitivity analysis should also be used to determine a few rules for the use of GENESYS. The established distance of influence of neighbouring fields and the results of Tables IV and V can also be used in a survey plan for gathering data for simulations with GENESYS. Again, the survey plan of the analysed fields destined, for instance, for evaluating the model (e.g. Colbach et al., 2005) or new cropping systems should be based on the temporal analysis to ensure that none of the main past events of the field history are neglected, while the minimum survey distance of neighbouring fields and borders should be based on the highrisk field plan. The analysis of the cultivation techniques revealed some to have little (e.g. grazing) or no effect (e.g. date of cutting). However, the method of cultivation should be recorded if available, as values are needed to make the model run. If they cannot be obtained, a mean regional input value may be used in the knowledge that the simulated output will not be significantly affected. Similarly, the survey plans will help the user to analyse the quality of GENESYS simulations according to the surveyed input variables. If, for instance, major variables such as cultivated crops or rape sowing dates could not be recorded during a survey, the simulated output would be much more affected than if the interviewed farmer did not remember how he tilled his field two or three years ago.

\section{CONCLUSION}

In contrast to most sensitivity analyses, the present study simultaneously evaluated the relative effects of all input variables on the simulated output. Its main results comprised the creation of a methodology for sensitivity analysis of spatiotemporal models, and the determination of the spatial and temporal extent of cropping system effects. The latter is necessary 
to determine practical advice for farmers who need to reduce harvest contamination of rape crops or to limit rape volunteer infestation in cereals. While the present study determined the importance of field patterns, it mostly concluded on the major and dominating effect of cropping systems, both in the non-GM growing fields and their neighbouring plots. The model should now be used for studies based on specific regional field patterns and farming systems to evaluate existing farming practices and to develop new cropping systems to reduce harvest contamination.

The present study was carried out for a given species, i.e. oilseed rape, for which gene flow occurs via both pollen and volunteer seeds. The conclusions would be very different for species such as maize, without viable volunteers under European conditions. Gene flow would be restricted to spatial spread, without transmission from one year to another. Consequently, the management and location of crops other than maize would be of no importance for gene flow while the annual precise location and management of the various maize fields would be crucial.

Acknowledgements: The authors are grateful to Pascal Neveu (ENSA Montpellier) for his help with manipulating the huge data sets with R and S+ procedures, and to Christophe Caron (INRA Jouy) for allowing the use of their server and his patient and very competent support when running the time- and space-greedy procedures. The present work was financed by INRA and the French Ministry of Research (ACI Impact des OGM).

\section{REFERENCES}

Angevin F., Colbach N., Meynard J.M., Roturier C. (2002) Analysis of necessary adjustements of farming practices, in: Bock A.-K., Lheureux K., Libeau-Dulos M., Nilsagard H., Rodriguez-Cerezo E. (Eds. and Synthesis), Scenarios for co-existence of genetically modified, conventional and organic crops in European agriculture, Technical Report Series of the Joint Research Center of the European Commission, EUR 20394 EN.

Bilsborrow P.E., Evans E.J., Bland B.F. (1994) Pollen transfer between high and low erucic acid oilseed rape crops, Aspects Appl. Biol. $40,143-149$.

Champolivier J., Messéan A. (2002) Dispersion du pollen de colza: contribution des observatoires de terrain, in: Séminaire de restitution des résultats de l'AIP "OGM et environnement", Paris 30 avril 2002, pp. 18-21.

Colbach N., Clermont-Dauphin C., Meynard J.M. (2001a) GENESYS: A model of the influence of cropping system on gene escape from herbicide tolerant rapeseed crops to rape volunteers. I. Temporal evolution of a population of rapeseed volunteers in a field, Agr. Ecosyst. Environ. 83, 235-253.

Colbach N., Clermont-Dauphin C., Meynard J.M. (2001b) GENESYS: A model of the influence of cropping system on gene escape from herbicide tolerant rapeseed crops to rape volunteers. II. Genetic exchanges among volunteer and cropped populations in a small region, Agr. Ecosyst. Environ. 83, 255-270.

Colbach N., Angevin F., Meynard J.M., Messéan A. (2004a) Using the GENESYS model quantifying the effect of cropping systems on gene escape from gm rape varieties to evaluate and design cropping systems, OCL 11, 11-20.

Colbach N., Molinari N., Clermont-Dauphin C. (2004b) Sensitivity analyses for a model simulating demography and genotype evolutions with time, Application to GENESYS modelling gene flow between rapeseed varieties and volunteers, Ecol. Model. 179, 91113.

Colbach N., Fargue A., Sausse C., Angevin F. (2005) Evaluation and use of a spatio-temporel model of cropping system effects on gene flow, Example of the GENESYS model applied to three co-existing herbicide tolerance transgenes, Eur. J. Agron. 22, 417-440.

Daniel C. (1973) One-at-a-time-plants, J. Am. Stat. Assoc. 68, 353-360.

Fargue A. (2002) Maîtrise des flux de gènes chez le colza : étude ex-ante de l'impact de différentes innovations variétales, Thèse INA P-G, Paris.

Fargue A., Meynard J.M., Colbach N., Vallée P., Grandeau G., Renard M. (2004) Contamination of rapeseed harvest by volunteers of other varieties: a study of intergenotypic competition, Eur. J. Agron. 21, 193-207.

Hamby D.M. (1994) A review of techniques for parameter sensitivity analysis of environmental models, Environ. Monit. Assess. 32, $135-154$.

Klein E. (2000) Estimation de la fonction de dispersion du pollen, Application à la dissémination de transgènes dans l'environnement, Thèse de doctorat, Université Paris-Sud.

Klein E.K., Lavigne C., Renard M., Gouyon P.H. (2005) Pollen dispersal of oilseed rape: estimation of the dispersal function and predicted effects of fields sizes on cross-pollination rates, J. Appl. Ecol.

Lavigne C., Klein E.K., Vallée P., Pierre J., Godelle B., Renard M. (1998) A pollen-dispersal experiment with transgenic oilseed rape, Estimation of the average pollen dispersal of an individual plant within a field, Theor. Appl. Gen. 96, 886-896.

Pekrun C., Lance P.W., Lutman P.J.W. (2005) Modelling seedbank dynamics of volunteer oilseed rape (Brassica napus), Agr. Syst. 84, 1-20.

Richter O., Seppelt R. (2004) Flow of genetic information through agricultural ecosystems: a generic modelling framework with application to pesticide-resistance weeds and genetically modified crops, Ecol. Model. 174, 55-66. 